\title{
A ABORDAGEM FREIREANA E A METODOLOGIA DE JIGSAW: UM RELATO DAS POTENCIALIDADES E LIMITAÇÕES PARA O ENSINO DE QUÍMICA
}

\author{
The freireana's approach and jigsaw methodology: a report on the potentialities \\ and limitations for Chemistry teaching \\ El enfoque freireana y la metodología de jigsaw: un relato de las potencialidades y \\ limitaciones para la enseñanza de Química
}

Jean Carlos Azevedo Penasso ${ }^{1}$

Adriana Marques de Oliveira²

\begin{abstract}
Resumo
O presente relato de pesquisa é resultado de uma sequência didática ancorada na perspectiva de Paulo Freire sob a educação humanística como forma de intervenção de mundo, e na aprendizagem cooperativa na qual a metodologia de Jigsaw está inserida. Foi desenvolvida com alunos do primeiro ano do Ensino Médio, de uma escola pública estadual da cidade de Dourados-MS. A temática desenvolvida foi "os raios, relâmpagos e trovões", na qual se trabalhou alguns conceitos químicos diretamente relacionados ao tema e ao referencial curricular. A pesquisa é de caráter qualitativo e quantitativo, e teve como metodologia de análise de dados a Análise Textual Discursiva (ATD). A partir da análise chegou-se e 2 categorias finais, nas quais deram origem a dois metatextos denominados: 1) Os fenômenos elétricos como agentes interferentes na natureza e na vida humana; 2) Conceitos químicos: campo elétrico, materiais condutores e isolantes. Diante os estudos e análises realizadas, a conciliação da perspectiva humanística com a aprendizagem cooperativa contribuiu para a formação de cidadãos críticos-reflexivos, e possibilitou investigar potencialidades e limitações dos referenciais utilizados durante a atividade.
\end{abstract}

PALAVRAS-CHAVE: Ensino. Aprendizagem cooperativa. Paulo Freire

\begin{abstract}
The present research report is the result of a didactic sequence anchored at the Paulo Freire's perspective under humanistic education as a form of world intervention, and in the cooperative learning in which the Jigsaw's methodology is inserted. It was developed with first-year high school students from a state public school in the city of Dourados-MS. The theme developed was "lightning, lightning and thunder", in which we worked on some chemical concepts directly related to the theme and the curricular reference. The research is of qualitative and quantitative nature, and had as methodology of data analysis the Discursive Textual Analysis (DTA). From the analysis came two final categories, in which they gave rise to two metatexts called: 1) Electrical phenomena as interfering agents in nature and in human life; 2) Chemical concepts:

\footnotetext{
1 Mestrando em Educação em Ciências na Universidade Federal do Mato Grosso do Sul - UFMS. Licenciado em Bacharelado/Licenciatura pela Universidade Federal da Grande Dourados -UFGD . Telefone: (67) 9973-8498. Email: jeanpenasso@ gmail.com

2 Professora Doutora da Universidade Federal da Grande Dourados - Ensino de Química da Faculdade de Ciências Exatas e Tecnologia - FACET da Universidade Federal da Grande Dourados. Telefone: (67) 9 99746760. Endereço: Universidade Federal da Grande Dourados - UFGD - Faculdade de Ciências Exatas e Tecnologia - FACET - Rodovia Dourados - Itahum, Km 12 - Caixa Postal -533- CEP: 79804-970 Dourados/MS. Email: adrianamarques@ufgd.edu.br
} 
electric field, conductive materials and insulation. Given the studies and analyzes carried out, the reconciliation of the humanistic perspective with the cooperative learning contributed to the formation of critical-reflexive citizens, and made it possible to investigate potentialities and limitations of the references used during the activity.

KEYWORD: Teaching. Cooperative learning. Paulo Freire

\section{Resumen}

El presente relato de investigación es el resultado de una secuencia didáctica anclada en la perspectiva de Paulo Freire bajo la educación humanística como forma de intervención del mundo y en el aprendizaje cooperativo en el que se inserta la metodología de Jigsaw. Fue desarrollada con alumnos del primer año de la Enseñanza Media, de una escuela pública estatal de la ciudad de Dourados-MS. La temática desarrollada fue "los rayos, relámpagos y truenos", en la cual se trabajó algunos conceptos químicos directamente relacionados al tema y al referencial curricular. La investigación es de carácter cualitativo y cuantitativo, y tuvo como metodología de análisis de datos la Análisis textual Discursivo (ATD). A partir del análisis se llegó y 2 categorías finales, en las que dieron origen a dos metatextos denominados: 1) los fenómenos eléctricos como agentes interferentes en la naturaleza y en la vida humana; 2) Conceptos químicos: campo eléctrico, materiales conductores y aislantes. Ante los estudios y análisis realizados, la conciliación de la perspectiva humanística con el aprendizaje cooperativo contribuyó a la formación de ciudadanos críticos-reflexivos, y posibilitó investigar potencialidades y limitaciones de los referenciales utilizados durante la actividad.

PALABRAS CLAVE: Enseñanza. Aprendizaje cooperativo. Paulo Freire

\section{INTRODUÇÃO}

Ser professor seria uma escolha ou uma habilidade na qual já se tem intrinsicamente desde o nascimento? Segundo Paulo Freire em sua obra "Pedagogia da Autonomia",o pensar certo implica em ter "consciência de mundo e a consciência de si como ser inacabado necessariamente inscrevem o ser consciente de sua inconclusão num permanente movimento de busca (FREIRE, 2014a, p. 56)". Neste sentido, independentemente do pensamento sobre o ato de ser professor, é de suma importância para qualquer profissional o caráter progressista em suas concepções educacionais. Assim, ser professor demanda muito mais do que uma escolha ou uma habilidade, demanda estudo, envolvimento, comprometimento, entre outros aspectos que buscam o que Freire denomina de "ser mais".

É de grande importância no ensino de química, a constante busca pela melhoria de propostas metodológicas, que auxiliem o professor em sala de aula. Coelho e Marques (2009), afirmam que a necessidade da mudança do ensino de química não se justifica apenas por orientações curriculares e convicções ideológicas, mas também do diagnóstico atual do ensino de química praticado no âmbito escolar. Na qual, deve estar voltado à formação para o exercício da cidadania, resultando assim num ensino transformador, logo, libertador.

Essa proposta didática consistiu na utilização da aprendizagem cooperativa, especificamente no formato da Metodologia de Jigsaw. Uma característica dessa metodologia de ensino consiste na sua perspectiva social, pois possibilita interações dialógicas dos alunos envolvidos, melhorando a compreensão individual e mútua (FATARELLI et al., 2010). Neste sentido social e dialógico, Freire (2014b) afirma que o diálogo deve servir como ferramenta social de crescimento existencial, e que para isso 
deve haver mais de um sujeito no processo. $\mathrm{O}$ autor também afirma que "somente o diálogo, que implica um pensar crítico, é capaz, também, de gerá-lo" (FREIRE, 2014b, p. 115).

Embasados na perspectiva freireana consideramos que tal temática parte da realidade dos estudantes. Nesse sentido, nos questionamos sobre a importância de tal abordagem no nosso contexto, a saber: a) Por que não partirmos de uma temática complexa, de algum composto químico recentemente descoberto? b) Por que não partirmos de uma temática considerada simples, de um fenômeno da natureza, que pode possibilitar uma vasta gama de diferentes abordagens tais como: científico, social, econômico e ambiental, como qualquer outro tema? c) Almeja-se demasiadamente a busca do conhecer o desconhecido, do novo, mas como poderemos buscar pelo novo, se mal compreendemos fenômenos do nosso cotidiano? d) Teríamos a oportunidade de estimularmos a criticidade por meio de abordagens da realidade do educando?

Tais questionamentos supracitados nos permitiram elaborar nossa questão básica, qual seja, "de que forma a perspectiva Freireana, articulada com a metodologia cooperativa de Jigsaw, podem proporcionar aos alunos do primeiro ano do Ensino Médio da rede pública estadual a compreensão de conceitos químicos utilizando como temática os fenômenos naturais elétricos?".

Deste modo, a proposta consiste em trabalhar com a temática de fenômenos naturais, especificamente os fenômenos elétricos: raios, trovões e relâmpagos. Embora essa temática esteja aparentemente relacionada diretamente com o ensino de física, podemos interligá-los a diversos fatores estudados e explicados pela química. A proposta versa em trabalhar alguns destes conceitos químicos envolvidos, com alunos do ensino médio público, possibilitando contribuições para o ensino de química.

\section{A concepção educacional de Paulo Freire}

Paulo Freire discute conceitos fundamentais para a compreensão de aspectos relacionados à educação e a sociedade. Nesse sentido, essa discussão buscará embasar tais conceitos para a tessitura deste trabalho.

Nesse intento, podemos afirmar que a educação seria um ato de intervenção no mundo? Segundo Freire (2014a) sim, e isso se deve a sua prática educativo-crítica, em que o conceito de intervenção no mundo deve ser utilizado amplamente, seja ela almejando mudanças no campo da economia, da saúde e da educação, visto que, nós, seres humanos não somos seres terminados, ou seja, sujeitos a vários fatores que nos afetam diretamente como a cultura, a sociedade, a história e os direitos. É importante frisar que tal intervenção também pode ter caráter de buscar imobilidade, priorizando a não melhoria dessas áreas incluindo não somente a educação.

Nesta perspectiva progressista, Paulo Freire (2014a) aponta que é necessário na formação inicial do docente o entendimento de quê se trata o ato de saber ensinar, do ser docente, onde o é preciso compreender e praticar o ato de que ensinar não é simplesmente transferir conhecimento, pois analisando o significado da palavra "transferir" o conhecimento deveria ser perdido do sujeito que o "transferiu", isso não ocorre. E como profissional este não deve ensinar o que não sabe, porém não deve somente saber o que irá falar diante os educandos, deve viver concretamente esta relação aluno-professor. 
Pesquisas realizadas por educadores químicos asseguram que à necessidade de mudanças no ensino de Química, e que um dos meios a contribuir para o ensino é introduzir no meio escolar os "temas químicos sociais", almejando estabelecer uma relação entre o conhecimento químico com problemas de relevância para a sociedade. A ideia consiste em romper com a visão errônea de que o conhecimento químico não está associado com a vida cotidiana (COELHO; MARQUES, 2009).

Assim, o professor deve criar possibilidades e utilizar metodologias potencializadoras para que os alunos construam seu próprio conhecimento, pois como sujeitos cognoscentes ${ }^{3}$, são capazes. Essas abordagens abrangem o desenvolvimento de habilidades nos educandos, como: a oratória e argumentação; o trabalho em grupo, no sentido de compreender e respeitar possíveis opiniões contrárias.

Desse modo, a abordagem Freireana aponta que o diálogo deve servir como ferramenta social de crescimento existencial, e que para isso deve haver mais de um sujeito no processo, de modo que essa perspectiva vai além do diálogo comum, onde um sujeito fala enquanto o outro, espera sua vez. A dialogicidade descrita por Freire se trata de uma educação humanista-libertadora, onde esta serve como um impulsionador do pensamento crítico-problematizador.

Segundo Mühl (2010), Freire afirma que o indivíduo problematizador realiza o hábito de perguntar não apenas como pergunta para o conhecimento, mas como algo que realiza a existência do ser humano. Assim, o ser problematizador do conhecimento se modifica da mesma maneira que este modifica o objeto de conhecimento. Neste sentido Oliveira e Recena (2014) afirmam que:

A prática problematizadora propõe aos homens a sua situação como problema e, assim, educadores e educandos fazem-se sujeitos de um processo de construção que desvela a realidade e insere o homem como um ser que está no mundo, sendo capaz de intervir na realidade (OLIVEIRA; RECENA, 2014, p. 104).

Neste movimento, o papel do educador não é de impor sua visão de mundo ao povo, mas sim por meio do diálogo problematizar concepções. Para isso é necessário bom-senso do educador, pois se tratando de seres humanos é preciso respeitar a dignidade do educando, para isso, o ponto inicial é considerar as condições por qual eles vêm, e principalmente reconhecer sua carga de conhecimentos/experiências quando este chega à escola. A não dialogicidade dessas percepções de mundo pode gerar a "educação bancária", descrita por Freire como uma doação dos que se julgam sábios aos que julgam nada saber ou ainda:

Imposição do conhecimento realizada pelo professor sobre o aluno na medida
em que o professor já os havia adquirido e dispõe destes sendo assim possível
sua ação de depósito deste conhecimento nos alunos (FREIRE, 2014b, p. 80).

Segundo Gonçalves (2015) uma das maneiras de superar essa barreira imposta pela educação bancária, é de realizar uma educação que possibilite a formação cidadã, onde está embasada na valorização das relações entre os conteúdos específicos e o contexto socioeconômico e cultural no qual os educandos estão inseridos.

\footnotetext{
3 Sujeitos cognoscentes são determinados como seres que possuem autonomia no seu processo de construção de conhecimento.
} 
Apesar de absurdamente equivocado a linha da educação bancária, onde o conhecimento é considerado algo a ser transferido ao educando, não obrigatoriamente, o aluno está condenado ao "saber bancário", isto porque não ao modo do ensino utilizado, mas ao seu eu que apresenta curiosidade, e que assim pode tornar-se um ser problematizador.

Neste viés, a função do educador é estimular a curiosidade através de perguntas que agucem a capacidade crítica sob o objeto e a reflexão crítica, de modo que os alunos se tornem sujeitos ativos e construtores de seu aprendizado. Retornamos ao fato da necessidade de uma educação dialógica, onde neste caso professor e aluno devem estar abertos ao diálogo, a curiosidade e a não passividade, se assumindo assim seres epistemologicamente curiosos.

Freire (2014a, p. 86) afirma que é "necessária promoção da curiosidade espontânea para a curiosidade epistemológica". Logo, a ruptura entre ambas não ocorre nesta perspectiva, visto que é descrito como um processo contínuo, pois a curiosidade epistemológica é vista como uma superação, e isso se dá quando a curiosidade ingênua passa a ser uma curiosidade criticizada.

Apesar de aparentemente serem os mesmos objetos de estudo, a aprendizagem cooperativa e a aprendizagem colaborativa possuem algumas especificidades que devem ser levados em consideração e que as tornam próximas, porém diferentes.

Silva (2011), afirma que ambas apresentam como princípio norteador para o processo de ensino-aprendizagem a interação social ${ }^{4}$ no meio educacional, fundamentando-se na teoria sociocultural do desenvolvimento cognitivo, entretanto, se distinguem na forma de promover este aprimoramento. Assim, apesar de semelhantes é necessário tratar ambas como elementos singulares.

O método cooperativo busca a interação social de modo que o professor utiliza a subdivisão de tarefas nos grupos, incentivando assim os educandos a participarem da aprendizagem dos colegas. Segundo as bases teóricas fornecidas por Johnson et al. (1999), para que o trabalho cooperativo seja funcional e produtivo, algumas condições precisam estar presentes no processo, como a interdependência positiva que consiste no trabalho em equipe para um objetivo comum, no qual cada um se preocupa com a aprendizagem dos colegas; a responsabilidade sob a própria aprendizagem e pela dos colegas e contribuição ativa para o grupo; a interação face a face, que possibilita a oportunidade de interagir com os colegas de modo a explicar, elaborar e relacionar conteúdos; as habilidades interpessoais que conferem as competências de comunicação, confiança, liderança, decisão e resolução de conflito; o processamento grupal no qual consiste no funcionamento sistemático do grupo e da progressão na aprendizagem.

Para Fiorentini (2006), para que um trabalho seja colaborativo, este deve ser constituído por pessoas voluntárias, ocorrendo à inibição de coação de alguém a tornálos participantes. Desse modo, podemos afirmar que um indivíduo participante de um grupo de trabalho que é cooperativo pode, porém nunca tornasse colaborativo.

Panitz (1997, apud HEERDT; BRANDT, 2008) acredita que é possível haver uma transição da aprendizagem cooperativa para a colaborativa. Isto porque, na cooperativa a formação de grupos possibilita que os educandos aprendam e

\footnotetext{
${ }^{4}$ A interação social corresponde a uma forma de compreender o processo de desenvolvimento cognitivo, pois imprime um caráter de coletividade sobre a dinâmica didática entre os protagonistas do processo ensino aprendizagem.
} 
compartilhem informações a partir das interações dialógicas, posteriormente quando essas informações começam geram um pensamento crítico mais elaborado, a aprendizagem desse momento começa a ser considerada colaborativa na qual $o$ compartilhamento de autoridade e aprendizagem entre professor e alunos ocorre.

Neste trabalho defendemos a importância da aprendizagem cooperativa para o ensino, pois a metodologia inserida nesse tipo de aprendizagem possui muitos fatores que contribuem para uma aprendizagem com ênfase nas relações sociais, na qual se aproxima com a perspectiva freireana discutida até o momento, e possibilita que os educandos compreendam a necessidade de compartilhamento de conhecimentos e responsabilidades em uma sociedade. Dentro desta perspectiva utilizaremos a Metodologia de Jigsaw, que busca justamente esta dinamização da necessidade das relações sociais.

O método Jigsaw utilizado neste trabalho pode ser definido como, um conjunto de procedimentos específicos ou fases, que possibilitam que os alunos trabalhem em grupos cooperativos, onde os afazeres de cada membro do grupo são essenciais para o sucesso final do trabalho, todo esse processo assemelha-se a um quebra-cabeça, pois só se conclui quando todas as peças estão encaixadas, dai a origem do nome Jigsaw, em inglês puzzle. Na primeira fase da metodologia cooperativa de Jigsaw, os alunos são divididos em grupos, chamados de grupos de base. Cada integrante do grupo recebe um subtópico a ser estudado. Na segunda fase, todos educandos de grupos de base existentes, que estudam a mesma temática, formam um grupo de estudo e discussão, este grupo denominado grupo de especialistas. Na terceira e última fase da metodologia, cada integrante retorna ao seu grupo de base compartilhando dialogicamente seu aprendizado com os demais colegas (TEODORO; CABRAL; QUEIROZ, 2015).

Deste modo, a temática raios, trovões e relâmpagos, a ser abordada neste trabalho, podem proporcionar grandes potencialidades para dialogicidade descrita por Freire, somada ao método cooperativo de Jigsaw. Pois, possibilita a discussão de vasta gama de diferentes abordagens tais como: científico, social, econômico e ambiental. Potencialidades essas que, implicam no desenvolvimento: da oratória e argumentação; no trabalho em grupo, no sentido de compreender e respeitar possíveis opiniões contrárias.

\section{Aspectos metodológicos}

O trabalho foi desenvolvido num período de três aulas de 50 minutos cada, no período matutino, com alunos do $1^{\circ}$ ano do ensino médio, na Escola Estadual Vilmar Vieira Matos, localizada na cidade de Dourados-MS. Os alunos participantes da atividade são de total 33 e possuem faixa etária de 15 a 16 anos. A sequência didática utilizada tem como suporte metodológico a aprendizagem cooperativa, especificamente a metodologia de Jigsaw (ARONSO, 1978), e também está amparada na perspectiva freireana na educação como prática de intervenção de mundo. A tabela 1 apresenta uma síntese das etapas realizadas durante a atividade em sala de aula.

Tabela 1: Síntese do planejamento didático

\begin{tabular}{|l|l|l|ll|}
\hline Etapas & Período & Atividade & Objetivos & \\
\hline $\begin{array}{l}\text { Primeira } \\
\text { etapa }\end{array}$ & $\begin{array}{l}\text { Uma hora- } \\
\text { aula }\end{array}$ & Apresentação do trabalho. & $\begin{array}{l}\text { Apresentação do trabalho a ser } \\
\text { desenvolvido }\end{array}$ \\
\hline
\end{tabular}




\begin{tabular}{|c|c|c|c|}
\hline & & Apresentação da temática & Inicio de reconhecimento da temática \\
\hline & & $\begin{array}{l}\text { Solicitar que os alunos } \\
\text { realizem questões sobre a } \\
\text { temática }\end{array}$ & $\begin{array}{l}\text { Investigar a opinião dos educandos, } \\
\text { para nortear a sequência didática. }\end{array}$ \\
\hline & & $\begin{array}{l}\text { Realizar questionamentos } \\
\text { iniciais }\end{array}$ & $\begin{array}{l}\text { Possibilitar maior interesse pela } \\
\text { temática. }\end{array}$ \\
\hline & & $\begin{array}{l}\text { Explicar a dinâmica de } \\
\text { atividade }\end{array}$ & $\begin{array}{l}\text { Possibilitar a visão geral do } \\
\text { funcionamento da atividade. }\end{array}$ \\
\hline & & $\begin{array}{l}\text { Formar grupos de base e } \\
\text { separar subtemas para } \\
\text { integrantes }\end{array}$ & $\begin{array}{l}\text { Viabilizar a dinâmica } \\
\text { funcionamento da metodologia }\end{array}$ \\
\hline $\begin{array}{l}\text { Segunda } \\
\text { etapa }\end{array}$ & $\begin{array}{l}\text { Uma hora- } \\
\text { aula }\end{array}$ & $\begin{array}{l}\text { Atividade em grupo de } \\
\text { especialistas }\end{array}$ & $\begin{array}{l}\text { Permitir o compartilhamento dos } \\
\text { conhecimentos possibilitando } \\
\text { desenvolvimento da oratória } \\
\text { argumentação }\end{array}$ \\
\hline & & & $\begin{array}{l}\text { Utilizar das relações sociais como } \\
\text { mecanismo para crescimento crítico- } \\
\text { social }\end{array}$ \\
\hline Terceira & Uma hora- & Atividade em grupos de base & Permitir aos educandos o \\
\hline & & $\begin{array}{l}\text { Discussão com todos os } \\
\text { educandos sobre as temáticas }\end{array}$ & conhecimentos \\
\hline
\end{tabular}

Fonte: Elaborado pelo autor.

Na etapa formar grupos de base e distribuir subtemas, solicitou-se a formação de seis grupos de cinco integrantes cada, dos quais cada integrante exercia a função de ser o responsável por uma temática, estas são: A importância desses fenômenos para a natureza; A luz e o som; A formação da carga; A condução da carga; Mortes e efeitos sobre o corpo humano. Destinou-se aos alunos a opção de escolha sobre sua temática de estudo. Para fins de organização, elaborou-se uma pequena tabela para que cada aluno registrasse qual era seu tema, tal documento ficou nas mãos do pesquisados.

A pesquisa quantitativa explora as características e situações que permitem a obtenção de dados numéricos, além de fazer uso de estatística para tais ações. Em contrapartida, a qualitativa explora características de indivíduos e cenários que não podem ser descritos facilmente a partir de números. Os dados são, em sua maioria, verbais, obtidos pela observação, descrição e através de gravação (MOREIRA e CALEFFE, 2008).

A Análise Textual Discursiva segundo Moraes e Galiazzi (2007), têm sido um dos métodos de análise mais utilizados em pesquisas qualitativas. Segundo os autores o objetivo deste tipo de análise não é comprovar hipóteses de resultados previamente descritos, pois a verdadeira intenção é a compreensão de maneira a reconstruir conhecimentos existentes sobre uma determinada temática de estudo. 
O objetivo dessa metodologia de análise se aproxima dos objetivos da pesquisa qualitativa, pois ambos afirmam que os resultados devem ser atingidos de maneira indutiva, visto que os resultados ou produtos do trabalho não podem ser previstos. Moraes e Galiazzi (2007), afirmam que a Análise Textual Discursiva está organizada em torno de quatro focos, a desmontagem de textos, o estabelecimento de relações, o captando o novo emergente e um processo auto-organizado. O processo em si, está voltado para os três primeiros, nos quais em conjunto, formam um ciclo de análise.

A etapa de desmontagem de textos, constituída pela desconstrução e unitarização, inicia-se com leitura e interpretação do chamado "corpus", o objeto de pesquisa, o texto, este é um processo no qual o pesquisador deve buscar sentidos e significados ao material textual constituído por significantes. Neste sentido é preciso perceber que todo material de leitura possibilita várias interpretações dos leitores que podem não conceber ao sentido do autor da escrita, Moraes e Galiazzi (2007) alegam que todo texto apresenta uma multiplicidade de leituras e que os resultados obtidos e compreendidos dependem tanto do pesquisador quanto dos autores dos textos.

Do processo de desconstrução surgem as unidades de significados ou de sentido, no processo de organização da análise sugere-se que um número ou letra seja atribuído a cada unidade de análise construída a partir de cada texto. Essas unidades podem ser definidas em função dos objetivos da pesquisa (MORAES; GALIAZZI, 2007).

O segundo foco da análise o estabelecimento de relações se dá pela categorização, segundo Moraes e Galiazzi (2007), este consiste no processo árduo de agrupar unidades significados, entretanto isso não implica em apenas reunir elementos semelhantes, mas também nomear e definir categorias no qual são de extrema importância para o próximo processo.

O terceiro foco de análise constitui-se no captar o Novo emergente, isso se dá pela construção de metatextos no qual se concretiza na descrição e interpretação, isso se deve aos processos anteriores, a unitarização e a categorização, estes compõem a estrutura básica do metatexto (MORAES; GALIAZZI, 2007). A produção do metatexto implica nas compreensões iniciais e parciais referente a cada categoria que foi determinada anteriormente.

O quarto e último foco da análise é a auto-organização, que se constitui na junção dos três processos anteriormente citados, e que na verdade está em todos os processos, pois é a partir dos resultados obtidos que o processo de organização é realizado. A Figura 1 apresenta a Análise Textual Discursiva como um ciclo em que há emergência de novas compreensões por meio dos três primeiros momentos citados.

Figura 1 Ciclo da Análise Textual Discursiva

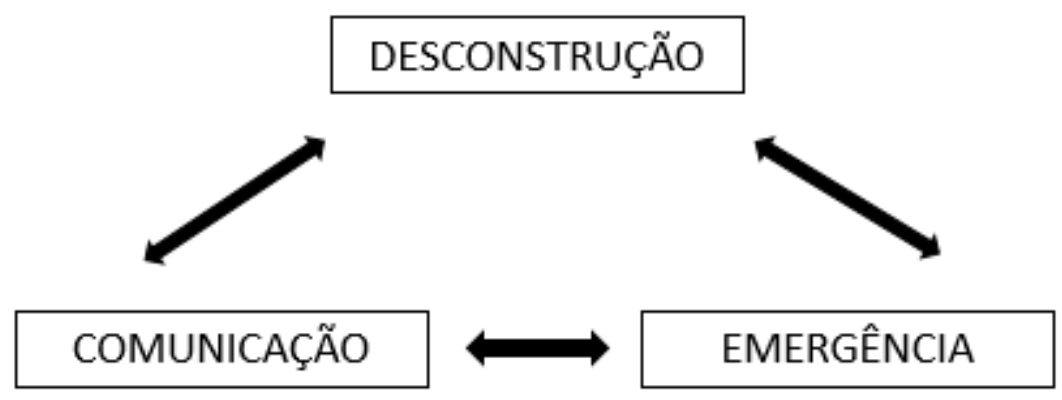

Fonte: MORAES e GALIAZZI, 2007, p. 41. 


\section{Resultados e discussões}

A primeira etapa do trabalho constituiu-se em solicitar aos alunos que escrevessem possíveis dúvidas, questionamentos e curiosidades a respeito da temática de fenômenos elétricos. A ação se deu como meio de aguçar o interesse pela temática, bem como iniciar o processo da transição da curiosidade espontânea para a curiosidade epistemológica, problematizada por Freire (2014a), onde o autor afirma que este é um processo de promoção na qual para o processo do pensamento criticizado e para a criatividade é essencial.

Algumas questões indagadas pelos alunos são: "As nuvens carregam cargas elétricas? Se sim, porque a chuva não é carregada?" "Por qual motivo, durante um trovão, sentimos um certo tremor ou vibração aqui na terra?" "Teria como "recebermos ou capitarmos" essas descargas elétricas?" Tais questões não foram analisadas neste trabalho de uma forma analítica, utilizando a metodologia da Análise Textual Discursiva, porém acredita-se que estas possuem grandes potencialidades de investigação e foram suportes para a realização da proposta ancorada nos referenciais escolhidos.

A construção dos metatextos se deve ao processo de desmontagem do "corpus", que consistiu em resumo/anotações sobre todos subtópicos trabalhados durante o processo. A partir de interpretações do pesquisador frente às unidades de significado dos alunos e agrupamentos realizados destas unidades semelhantes chegou-se a 7 categorias iniciais, 4 categorias intermediárias e 2 categorias finais. $\mathrm{O}$ gráfico 1 abaixo expressa a quantidade de unidades significado em cada categoria final emergida diante a metodologia de análise.

\section{Gráfico 1: Unidades de significado constituintes das categorias finais emergidas}

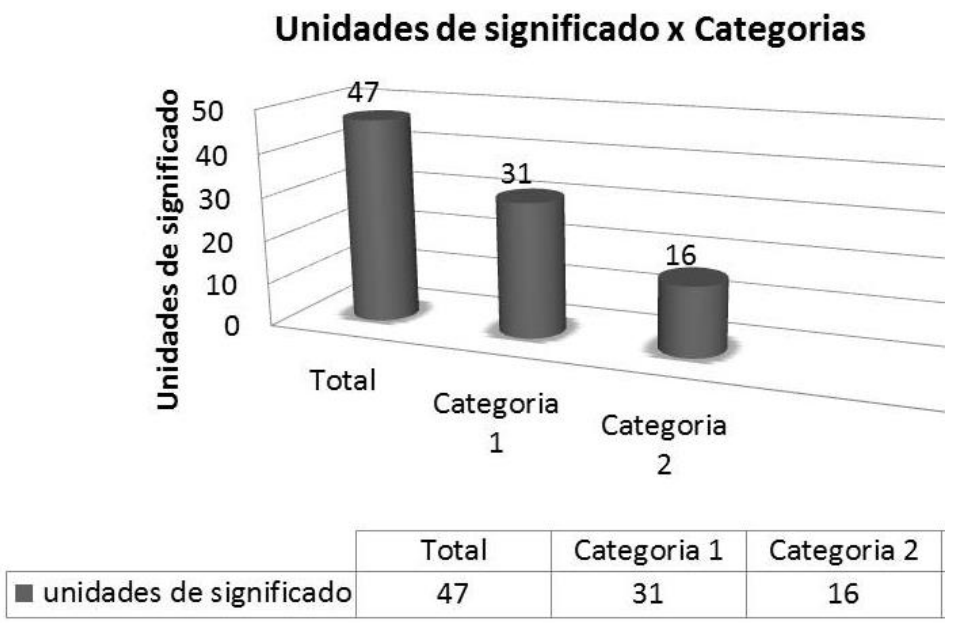

Fonte: Desenvolvido pelo pesquisador

Tais categorias finais deram origem ao título dos dois metatextos intitulados: 1) Os fenômenos elétricos como agentes interferentes na natureza e na vida humana; 2) Conceitos químicos: campo elétrico, materiais condutores e isolantes.. 
Entre os muitos fenômenos da natureza, os que despertam grande interesse pelas pessoas são os raios, relâmpagos e trovões. Isso se deve tanto pela beleza dos fenômenos com desenhos enigmáticos no céu escuro devido tempestades, como o medo advindo da intensidade dos mesmos. Segundo Silva (2007), várias foram as tentativas de explicar esses fenômenos, entre eles destacam-se as crenças de algumas civilizações antigas que acreditavam que esses fenômenos estavam associados a manifestações de fúria de seus deuses, devidas ações realizadas por alguns membros que teriam sido desagradáveis aos seus deuses. Ainda hoje, esses fenômenos são utilizados como fatores de mistério e suspense em filmes e séries como exemplos de força da natureza.

É importante frisar que as seguintes unidades de significado que serão abordadas, não se consideraram possíveis erros conceituais, mas sim a dinâmica das concepções entre os alunos. Mediante a aplicação da atividade com a metodologia de Jigsaw, podemos observar alguns apontamentos dos alunos mediante o assunto de fenômenos elétricos: "os incêndios produzidos pelos relâmpagos podem produzir uma reciclagem de nutrientes do solo, o que favorece a perpetuação não só de espécies regulares como também animais (5.1.1)”.

Podemos observar que o aluno faz referência à importância do relâmpago como causador de incêndios, que por sua vez exerce função de fertilizar o solo. No mesmo sentido, temos a escrita de outro aluno sobre a mesma temática:

"os incêndios produzidos pelos relâmpagos podem produzir uma reciclagem de nutrientes do solo, o que favorece a perpetuação não só de espécies regulares como também animais. Os relâmpagos tem um papel importante no equilíbrio químico da atmosfera (3.1.1)".

Podemos observar que esses alunos de grupos diferentes fazem associação dos incêndios ligados aos relâmpagos como modo de reciclagem de nutrientes no solo e que isso é um fator importante para a perpetuação das espécies terrestres. Entretanto, podemos notar que nenhum aluno faz referencia aos incêndios ou queimadas provocadas criminalmente, na qual visa apenas a limpeza do local para atividades de interesse econômico.

Um fator importante a ser observado é que o educando 3.1.1, cita a importância do relâmpago para o equilíbrio da atmosfera, neste viés, poderíamos afirmar que a metodologia possui limitações diante a escrita diferente desse aluno? Pois, sabendo que um aluno se aprofundou mais sobre a temática. O aluno 1.1.1 relata outras contribuições sobre o assunto:

os relâmpagos modificam o equilíbrio da atmosfera em volta dos locais onde elas ocorrem, pois dão origem ao óxido de nitrogênio, por sua vez se combinam dando origem a novos elementos como o ozônio que é muito importante, pois funciona como um escudo contra a radiação ultravioleta (1.1.1).

Este educando dá maior ênfase a importância do relâmpago para a atmosfera e também já cita o ozônio como um "escudo" para radiação ultravioleta, demonstrando assim preocupação com a vida terrestre. Neste sentido podemos relacionar essa escrita, com a escrita do educando que comenta a importância do raio para incêndios que propicia a perpetuação das espécies. Ambos comentam sobre a preocupação sobre a vida, algumas escritas citam problemas vindos desses fenômenos com maior ênfase a saúde humana: "O raio muitas vezes pode ser fatal, mas depende do jeito que ele cai. Se a pessoa não morrer ela sofre lesões no corpo como queimaduras, lesões cardiovasculares e entre outras (5.1.3)".

Podemos observar que o educando fala sobre os efeitos do raio sobre o corpo do 
ser humano, mas a interpretação que se pode ter é que está muito superficial, podemos associar esse fator à concepção de Freire sobre a curiosidade espontânea que deve ser superada ao ponto de chegarmos à curiosidade epistemológica, onde essa transição se dá pelo processo onde a curiosidade ingênua passa a ser uma curiosidade criticizada. Podemos observar a escrita de outro aluno: "Ao ser atingido por um raio, uma pessoa pode sofrer diversos tipos de lesões dentre elas estão: queimaduras, efeito neurológico, lesões cardiovasculares, lesões respiratórias e efeitos neuro-sensorias (4.1.2)”.

Nota-se que apesar de não se referir à fatalidade ligada ao fenômeno, o educando traz muitos outros efeitos que podem ser causados pelo raio. A estrutura espacial da nuvem é relativamente grande, dentro da nuvem é constante a movimentação de partículas de água, gelo, gases, devido aos fortes ventos e variação de temperaturas. Durante esse processo ocorrem colisões entre as partículas de gelo, esse atrito realizado entre as partículas formam cargas iônicas, tornando assim a nuvem carregada eletricamente. Podemos observar que alguns educandos fazem referencia a está hipótese: "Durante colisões, as partículas de gelo perdem elétrons e transformam-se em ions. Isso torna a nuvem eletricamente carregada (4.1.3)".

Já o aluno 4.2.4 pertencente ao mesmo grupo faz referência ao fenômeno de formação da carga de outro modo: "As cargas se formam após o atrito de partículas de gelo no interior da nuvem, formando cátion e ânions, que se unem em pontos específicos da nuvem, assim ela fica eletricamente carregada (4.2.4)”.

Observa-se que ambos os alunos pertencentes ao mesmo grupo de base citam a formação de componentes eletricamente carregados e que tais possibilitam que a nuvem toda se torne carregada, porém o aluno 2, descreve mais sobre o fenômeno que o aluno 1. Podemos alegar falta de cooperação? Falta de diálogo? Freire (2014b) aponta o diálogo como uma ferramenta social de crescimento existencial, onde sujeitos devem estar inseridos no processo que deve ir além do diálogo comum, onde um sujeito fala enquanto o outro, espera sua vez. A dialogicidade descrita pelo autor se trata de uma educação humanista-libertadora, onde esta serve como um impulsionador do pensamento crítico-problematizador.

É necessário relatar que em diversos grupos de base houve descrições idênticas sobre o mesmo assunto, porém houve eventuais grupos na qual estavam diferentes. Já as observações feitas quando trata-se de grupos de especialistas, no geral, descrevem sobre o mesmo assunto, porém com níveis de aprofundamento diferente.

Neste sentido podemos retomar as concepções de Panitz (1997) na qual acredita que é possível haver uma transição da aprendizagem cooperativa para a colaborativa. A atividade de cooperação está na formação de grupos de especialistas que são definidos por integrantes aleatórios, estudantes que escolheram o mesmo subtema.

$\mathrm{O}$ autor defende que este momento possibilita que os educandos aprendam e compartilhem informações a partir das interações dialógicas, posteriormente quando essas informações começam geram um pensamento crítico mais elaborado, a aprendizagem desse momento começa a ser considerada colaborativa na qual o compartilhamento de autoridade e aprendizagem entre professor e alunos ocorre. Neste viés podemos considerar que a metodologia cooperativa permanece presente diante a estrutura dada a movimentação de membros entre grupos, e que a colaborativa caminha juntamente com esta.

Poderíamos então afirmar que as respostas divergentes se devem ao não compartilhamento de tais informações? Ou seria algo que na visão do educando filtrou 
informações importantes a ele? Freire (2014a) afirma que o educando visto como ser cognoscente, exercendo um papel crítico sobre um determinado assunto, pensa sobre as informações da mesma, mas cabe a ele e somente a ele, descrever sobre aquilo que lhe é pertinente. Neste sentido, apesar de escritas diferentes, não necessariamente não houve discussão e troca de informações sobre a mesma.

\section{CONSIDERAÇÕES FINAIS}

A pesquisa buscou desenvolver uma sequência didática na qual busca compreender como a perspectiva Freireana da educação dialógica, articulada com a aprendizagem cooperativa de Jigsaw podem auxiliar os alunos a aprenderem conceitos químicos numa perspectiva humanística.

Durante a execução da sequência apresentada muitos fatores concomitantes contribuíram negativamente para a delimitação de limitações da sequência didática realizada. A atividade foi desenvolvida em três dias diferentes, devido a esse fator a presença de todos alunos em todos os dias não ocorreu, por exemplo na segunda etapa de atividade cinco alunos faltaram. Isso prejudicou não apenas o aluno faltante, mas todo o grupo no qual este pertence, visto que a metodologia possibilita e enfatiza a necessidade de cada indivíduo para a realização do todo.

A sala era composta com 33 alunos, um número grande, onde a dinâmica de se trabalhar com grupos torna-se mais difícil, pois como ainda muito jovens os alunos gostam de brincadeiras e momentos de descontração. A dificuldade deles de trabalharem em grupo também foi perceptível, alunos que perderam a folha de texto, alunos que esqueceram, etc. Podemos fazer associação de que o interesse pelo bem do grupo é um pouco deixado de lado neste sentido.

Um dos fatores que mais limitaram a sequência foi o cronológico, não necessariamente da atividade em si, mas sim o tempo gasto pelos alunos para realizarem algo que não exigiria o tempo utilizado. Isso se deve a falta de experiência do pesquisador com atividades desse modelo, e também a própria conversa entre os alunos, pois a formação de grupos propicia maior facilidade.

A perspectiva de Paulo Freire, tendo a educação amparada no caráter humanístico contribuiu muito para o embasamento da necessidade de um ensino pautado sob a perspectiva social, onde o indivíduo é visto como um "nós", ou seja, o indivíduo é único, porém seu "único" é formado por muitos outros indivíduos nos quais ele está diretamente ou indiretamente conectado a ele.

A metodologia de Jigsaw advinda da aprendizagem cooperativa apresenta grandes potencialidades, bem como limitações. Realmente como descrito por teóricos, ela propicia aos alunos a oportunidade de ensinar e aprender uns com os outros, conduzindo, explicando e ajudando na compreensão de temas com colegas, numa atmosfera de companheirismo, descontração e interação. Podemos observar que a metodologia promove o desenvolvimento de habilidades na comunicação oral e no campo social, pois os alunos são distribuídos com colegas de classe das quais não foram escolhidos, para que assim num segundo momento trabalhe com seus colegas mais próximos.

Sobre as limitações encontradas, podemos apontar que durante a pesquisa foi possível observar que esse tipo de atividade exige do professor uma organização da turma e requer mais pesquisas e planejamento e aperfeiçoamento individual para cada turma, e que a turma deve colaborar, nesta atividade o caráter de maturidade dos alunos frente à proposta afeta diretamente na dinâmica utilizada, pois a atividade exige grande responsabilidade por parte dos alunos sob a própria aprendizagem e pela dos colegas e contribuição ativa para o grupo.

Através da ATD, houve a possibilidade de tratar os dados da pesquisa, retirados de anotações solicitadas aos alunos, pôde-se compreender e interpretar os entendimentos dos 
educandos acerca da temática abordada, possibilitando assim a busca pela compreensão das potencialidades e limitações da atividade proposta. Tornou-se possível verificar se os alunos passaram a ter maior interesse pela temática, bem como criticizá-la.

Concluímos que por meio das análises realizadas, a proposta possui grandes contribuições para o ensino de química e também para o ensino de outras áreas, pois enfatiza o caráter social, no qual tende buscar por cidadãos conscientes da necessidade do compartilhamento de conhecimentos e responsabilidades em sociedade.

\section{REFERÊNCIAS}

COELHO, J. C.; MARQUES, C. A. Contribuições freireanas para a contextualização no ensino de Química. Ensaio Pesquisa em Educação em Ciências, Belo Horizonte, v. 9, n. 1, p. 49-61, 2009.

FIORENTINI, Dario. Pesquisar práticas colaborativas ou pesquisar colaborativamente? In: BORBA, M. C., LOILA, J. Pesquisa Qualitativa em Educação Matemática. Belo Horizonte: Autêntica, 2a Ed. 2006.

FREIRE, P. Pedagogia da Autonomia: saberes necessários à prática educativa. Rio de Janeiro, Paz e Terra. 2014 a.

FREIRE, P. Pedagogia do oprimido. Rio de janeiro. Paz e Terra, 2014b.

GONÇALVES, C. Utilização do formol em alisamento capilar para ensinar conceitos de ligações intermoleculares sob a perspectiva freireana. TCC (Graduação em química) - Universidade Federal da Grande Dourados, Dourados. 2015.

HEERDT, B.; BRANDT, C. F. Aprendizagem cooperativa/colaborativa com o uso da webquest em aulas de biologia. ANPEDSUL. VII Seminário de pesquisa em educação da Região Sul. Pesquisa em educação e inserção social. UNIVALE. Itajaí. Santa Catarina. 2008.

JOHNSON, D.W.; JOHNSON, R.T.; HOLUBEC, E.J. Los nuevos círculos delaprendizaje: lacooperaciónenel aula y laescuela. Virginia: Aique, 1999.

MORAES, R; GALIAZZI, M.C. Análise Textual Discursiva. ed.Unijuí, 2007.

MOREIRA, H.; CALEFFE, L.G. Metodologia da pesquisa para o professor pesquisador. 2. Ed., Rio de janeiro: Lamparina, 2008.

MÜHL, E. H. Problematização. In: STRECK, D. R.; REDIN, E.; ZITKOSKI, J. J. (Org.) Dicionário Paulo Freire. Belo Horizonte, Autêntica, 2010.

OLIVEIRA, A. M.; RECINA, M. C. P. O ensino de polímeros na perspectiva da educação dialógica com enfoque em CTS. Alexandria Revista de Educação em Ciência e Tecnologia, v.7, n.1, p.103-126, mai. 2014.

SILVA, E. S. A física dos relâmpagos e dos raios. TCC (Graduação em física) Universidade Católica de Brasília, Brasília. 2007.

SILVA, V. A. A aprendizagem colaborativa como método de apropriação do conhecimento químico em sala de aula. Dissertação (Mestrado em Educação Em Ciências E Matemática) - Universidade Federal De Goiás, Goiânia. 2011.

TEODORO, D. L.; CABRAL, P. F. O.; QUEIROZ, S. L., Atividade cooperativa no formato Jigsaw: Um estudo no ensino superior de química. Alexandria Revista de Educação em Ciência e Tecnologia, v. 8, n. 1, p. 21-51, 2015. 
Recebido em: 20/06/2017

Aprovado em: 25/07/2017 